\title{
Porównanie energetycznego modelu wyznaczania trwałości zmęczeniowej złączy spawanych z zaleceniami międzynarodowymi
}

\author{
Comparison of energetic approach to international \\ recommendations for fatigue analysis of welded joints
}

\section{Streszczenie}

W pracy przedstawiono model energetyczny wyznaczania trwałości zmęczeniowej, odniesiony do problemu wyznaczania trwałości złączy spawanych. Zaproponowano połączenie modelu energetycznego opisanego już w literaturze $z$ metodą zastępczego jednostkowego promienia zaokrąglenia. Obliczenia przeprowadzono dla krzyżowego złącza spawanego przy obciążeniach stałoamplitudowych (wahadłowe rozciąganie-ściskanie). Dodatkowo, dla celów porównawczych, przeprowadzono obliczenia dla dwóch metod uwzględnionych w zaleceniach międzynarodowych: metody naprężeń nominalnych oraz metody zastępczego jednostkowego promienia zaokragglenia. Otrzymane wyniki obliczeń zostały porównane z wynikami badań eksperymentalnych. Wykazano dużą zgodność wyników obliczeń według zaproponowanego modelu energetycznego z wynikami eksperymentalnymi.

\section{Wstęp}

Charakterystyczna mikrostruktura i złożoność kształtu złącza spawanego jest źródłem koncentracji naprężeń. Właściwość ta wskazuje na złącza spawane jako miejsce, od którego zaczyna się proces niszczenia danej konstrukcji. Badania zmęczeniowe wykazują brak wpływu rodzaju stalowego materiału rodzimego na trwałość zmęczeniową [1, 2]. Cechę tę należy wziąć

Mgr inż. Łukasz Blacha, dr hab. inż. Aleksander Karolczuk - Politechnika Opolska.

\section{Abstract}

An energetic approach for fatigue analysis of welded joints is presented in this paper. Calculations were carried out for transverse stiffener welded element from S355N steel, submitted to fully reversed constant amplitude tension-compression loading. In order to address the issue of stress state in a weld notch, combination of energetic model and effective notch stress method for fatigue analysis is proposed. Procedures that were undertaken and introduced in this study are based on critical plane criterion of fatigue failure for life prediction. Critical plane orientation was determined by the direction of normal vector which is the same as the first principal direction. It is an improvement of the energetic model already proposed in the literature for structural elements.

To further illustrate the effectiveness of the presented procedures, fatigue resistance against nominal stress and effective notch stress (fictitious notch radius) was evaluated, according to recommendations from International Institute of Welding. All the calculated fatigue lives were compared to test results. The presented energetic model produced results which closely resemble fatigue test results.

pod uwagę przy projektowaniu konstrukcji, które będą poddane obciążeniom zmiennym. Wyznaczanie trwałości zmęczeniowej złączy spawanych jest problemem złożonym, dlatego też opracowano wiele metod obliczeniowych. W pracy zaprezentowano skrócony opis trzech metod oceny trwałości zmęczeniowej złączy spawanych, opartych na następujących parametrach: naprężeniu nominalnym (a), naprężeniu $w$ dnie karbu z fikcyjnym promieniem zaokrąglenia (b) gęstości energii odkształceń (c). Metody oparte na parametrach a oraz b zostały włączone do metod zalecanych przez Międzynarodowy Instytut Spawalnictwa (IIW) [3]. Szczególną uwagę poświęcono modelowi energetycznemu wyznaczania trwałości zmęczeniowej opartemu na parametrze c. Przy zastosowaniu przyjętych metod 


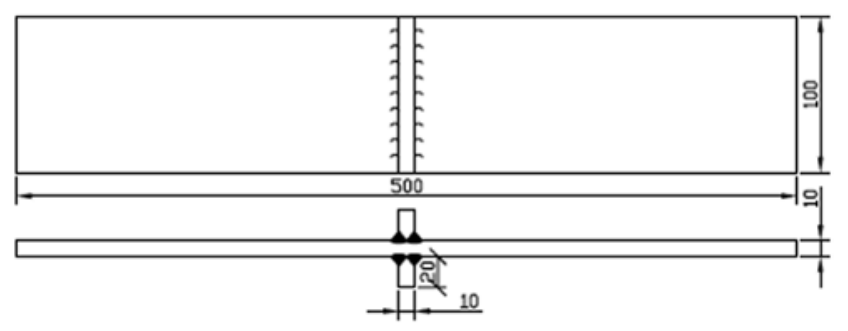

Rys. 1. Kształt badanego elementu ze złączem spawanym Fig. 1. Shape of investigated welded element

przeprowadzono ocenę trwałości zmęczeniowej krzyżowego złącza spawanego (rys. 1) ze stali S355N (materiał rodzimy). Otrzymane wyniki trwałości porównane zostały z wynikami badań eksperymentalnych [1]. $\mathrm{Na}$ rysunku 1 przedstawiono kształt elementu z badanym złączem spawanym. Element spawany poddany był rozciąganiu-ściskaniu o cyklu wahadłowym.

Celem opracowania jest: przedstawienie metody oceny trwałości zmęczeniowej będącej połączeniem modelu energetycznego $z$ metodą promienia fikcyjnego, zastosowanie modelu energetycznego do wyznaczania trwałości zmęczeniowej krzyżowego złącza spawanego i porównanie tak wyznaczonej trwałości z wynikami badań eksperymentalnych oraz z trwałością obliczeniową wyznaczoną zgodnie z zaleceniami Międzynarodowego Instytutu Spawalnictwa.

\section{Metoda naprężeń nominalnych}

Metoda naprężeń nominalnych wymieniana jest w wielu zaleceniach międzynarodowych, między innymi w zaleceniach Międzynarodowego Instytutu Spawalnictwa [3], normach europejskich [4] oraz normach japońskich [5]. Ocena trwałości zmęczeniowej przy wykorzystaniu metody naprężeń nominalnych jest preferowana dla złączy spawanych występujących w sklasyfikowanych elementach spawanych. Idea tej metody sprowadza się do konieczności wyboru przez projektanta odpowiedniej klasy, do której przypisuje się rozważany element ze złączem spawanym. Dobór klasy podyktowany jest głównie kształtem elementu oraz sposobem obciążenia. Trwałość zmęczeniową wyznacza się w oparciu o naprężeniowy parametr uszkodzenia oraz charakterystykę zmęczeniową w postaci wykresu Wöhlera w skali podwójnie logarytmicznej.

Parametrem uszkodzenia w metodzie naprężeń nominalnych jest zakres naprężeń $\Delta \sigma$, które z kolei wyznacza się przy pominięciu efektu koncentracji naprężeń pochodzących od złącza spawanego (naprężenia nominalne). Element spawany przypisuje się do jednego ze sklasyfikowanych przypadków - klasy (liczby) FAT jako odnośnika do charakterystyki zmęczeniowej. Liczba FAT oznacza zakres naprężeń nominalnych $\Delta \sigma=$ FAT, przy których trwałość złącza wynosi $2 \times 10^{6}$ cykli. W innych międzynarodowych zaleceniach $[4,5]$ wyznaczenie parametru również jest oarte na o podziale charakterystyk wg klas.
Liczba cykli do zniszczenia $N_{f}$ wg zaleceń IIW wyznacza się na podstawie zależności

$$
N_{f}=\left(\frac{F A T}{\Delta \sigma}\right)^{m} \cdot 2 \cdot 10^{6}=\left(\frac{F A T}{2 \sigma_{\text {an }}}\right)^{m} \cdot 2 \cdot 10^{6}
$$

Trwałość zmęczeniowa wyznaczona w ten sposób w założeniach IIW charakteryzuje się prawdopodobieństwem zniszczenia na poziomie pięciu procent $\left(p_{f}=5 \%\right)$. W zaleceniach IIW [3] charakterystyki zmęczeniowe do zakresu $10^{7}$ cykli w większości przypadków mają nachylenie (współczynnik kierunkowy) $m=3$, przy czym górnym ograniczeniem jest charakterystyka zmęczeniowa materiału rodzimego. Do zastosowań gigacyklowych (zakres od $10^{7}$ cykli) przyjmuje się nachylenie charakterystyk zmęczeniowych przy $m=22$. Do elementów walcowanych lub wyciskanych, elementów z krawędziami obrobionymi oraz bezszwowych elementów drążonych przypisane są wartości $m=5$ (do zakresu $10^{8}$ cykli, przy ograniczeniu jw.) i $m=22$ (zastosowania gigacyklowe, zakres od $10^{8}$ cykli). Szczegółowe omówienie zagadnień związanych z zastosowaniem metody naprężeń nominalnych wg IIW zamieszczono w pracy [6], natomiast trudności dotyczące doboru odpowiedniej klasy zmęczeniowej opisane są w [7].

Metoda naprężeń nominalnych pozwala na szybką ocenę trwałości zmęczeniowej złączy spawanych występujących w sklasyfikowanych elementach spawanych.

\section{Metoda promienia fikcyjnego}

W metodzie promienia fikcyjnego parametrem uszkodzenia jest zakres naprężeń w dnie karbu z fikcyjnym jednostkowym promieniem zaokrąglenia $\rho_{f}$. Taka postać zaokrąglenia jest formą idealizacji warunków rzeczywistych, z tego powodu naprężenia wyznacza się numerycznie, metodą elementów skończonych. Obliczenia wykonuje się z wykorzystaniem analizy liniowej (wg modelu ciała liniowo sprężystego) przeprowadzanej dla modelu dyskretnego z przypisanymi izotropowymi właściwościami materiału i opartego na geometrii uwzględniającej promień $\rho_{f}$ w linii wtopu. Przykładowy model dyskretny uwzględniający fikcyjny promień zaokrąglenia przedstawiono na rysunku 2.

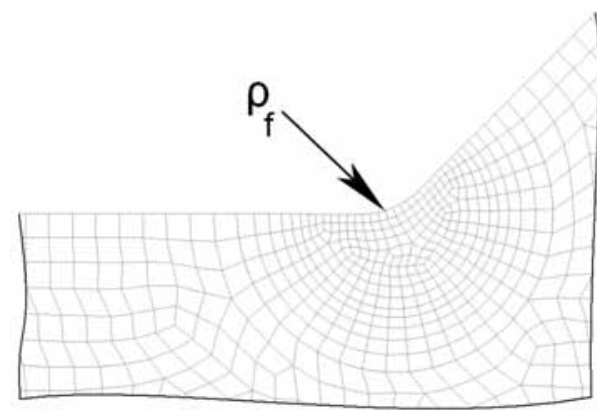

Rys. 2. Siatka elementów skończonych uwzględniająca fikcyjny promień zaokrąglenia $\rho_{f}$ w linii wtopienia

Fig. 2. Mesh of discrete model with fictitious notch rounding $\rho_{f}$ at the fusion line 
Dla stali konstrukcyjnych i aluminium zaleca się wartość $\rho_{f}=1 \mathrm{~mm}$ [3]. Metoda (jednostkowego) promienia fikcyjnego jest jedną z metod przedstawionych w zaleceniach IIW pod nazwą effective notch stress. Do wyznaczenia trwałości zmęczeniowej złączy spawanych przy wykorzystaniu metody promienia fikcyjnego stosuje się charakterystyki zmęczeniowe FAT 225 dla stalowych złączy spawanych oraz FAT 71 dla aluminium. Nachylenie w obu przypadkach wynosi $m=3$ (zakres do $10^{7}$ cykli). Ponieważ metoda ta dotyczy złączy spawanych bez dalszej obróbki cieplnej, efekt obecności naprężeń własnych ma odniesienie w charakterystyce zmęczeniowej [8]. W założeniach IIW tak wyznaczona trwałość zmęczeniowa charakteryzuje się prawdopodobieństwem zniszczenia $p_{f}=5 \%$. Metoda ta ma ograniczenie do elementów o grubości $\min .5 \mathrm{~mm}[3,8,9]$.

Idea metody promienia fikcyjnego wywodzi się z koncepcji uśredniania naprężeń zaproponowanej przez Neubera [10]. Koncepcja ta prowadzi do następującej zależności:

$$
\rho_{f}=\rho+s \cdot \rho^{*}
$$

gdzie: $\rho$ - rzeczywisty promień zaokrąglenia, $s$ - współczynnik wieloosiowości, $\rho^{\star}$ - zastępcza długość mikrostrukturalna.

Współczynnik wieloosiowości $s$ zależny jest od geometrii, rodzaju obciążenia oraz rodzaju przyjętego kryterium wytężenia materiału, według którego wyznacza się wartość parametru uszkodzenia. Zalecenia IIW oparte są na kryterium Hubera-Misesa-Hencky'ego.

Zastępcza długość mikrostrukturalna $\rho^{*}$ zależy od struktury materiałowej, przy czym można ją przedstawić jako funkcję granicy plastyczności, zgodnie z oryginalną koncepcją Neubera [11]. Wykres do wyznaczania wartości parametru można znaleźć w pracy [2], rozważania dotyczące metody Neubera w $[6,8]$, a analizę wyznaczania pól naprężeń w [11].

Wartość $\rho_{f}$ równa $1 \mathrm{~mm}$ wyznaczona została przy następujących założeniach: $s$ równe 2,5 (kryterium wytężeniowe Hubera-Misesa-Hencky'ego), wartość $\rho^{*}$ dla różnych stali konstrukcyjnych przyjęto na stałym poziomie równym $0,4 \mathrm{~mm}$, obecność karbu ostrego $(\rho=0 \mathrm{~mm})$, przyłożone obciążenie to rozciąganie, ściskanie lub zginanie, płaski stan naprężenia na powierzchni elementu. W przypadku elementów o przekroju okrągłym (przestrzenny stan naprężenia) współczynnik wieloosiowości s równy jest jedności.

W celu obliczenia parametru uszkodzenia określić należy ekwiwalentne naprężenia $\sigma_{e q} \mathrm{w}$ dnie tak zamodelowanego karbu, zredukowane wg hipotezy Hubera-Misesa-Hencky'ego i zapisane w postaci zakresu naprężeń. Zastosowanie innego kryterium wytężenia materiału pociąga za sobą zmianę wartości współczynnika wieloosiowości $s$ - wartości wskazane są w $[2,10]$.

Jednostkowy promień $\rho_{f}$ jest wartością graniczną dla aluminiowych złączy spawanych, jednak przyjęty został ze względu na konieczność ujednolicenia zaleceń [8].

\section{Model energetyczny}

W modelu energetycznym do opisu wieloosiowego zmęczenia stosuje się kryteria oparte na energii odkształceń sprężystych, odkształceń plastycznych oraz na sumie odkształceń sprężystych i plastycznych. Ocena trwałości zmęczeniowej przy wykorzystaniu modelu energetycznego opiera się na wyznaczeniu wartości odpowiednio sformułowanego energetycznego parametru uszkodzenia [12].

Do obliczeń wykorzystano parametr energetyczny sformułowany dla zakresu sprężystego. Opisywany energetyczny model zniszczenia zmęczeniowego opiera się na parametrze gęstości energii odkształceń normalnych w płaszczyźnie krytycznej [12]. Założeniem dla tego kryterium jest, że pękanie zmęczeniowe opisane jest przez parametr gęstości energii odkształceń normalnych $W_{\eta}$, na płaszczyźnie krytycznej [12], którą można zdefiniować jako płaszczyznę, w której występuje największa wartość parametru energetycznego $W_{n}$. Skrócony algorytm wyznaczania trwałości zmęczeniowej w warunkach obciążeń stałoamplitudowych według modelu energetycznego przedstawiono na rysunku 3 . Parametr $W_{\eta}$ gęstości energii odkształcenia normalnego w postaci zaproponowanej przez Łagodę [12] można zapisać za pomocą wyrażenia

$$
W_{\eta}=\frac{1}{2} \cdot \sigma_{\eta}(t) \cdot \varepsilon_{\eta}(t) \cdot \operatorname{sgn}\left(\sigma_{\eta}, \varepsilon_{\eta}\right)
$$

gdzie: $\sigma_{\eta}, \varepsilon_{\eta}$ - naprężenie, odkształcenie normalne, na płaszczyźnie krytycznej,

$$
\operatorname{sgn}(x, y)=\frac{\operatorname{sgn}(x)+\operatorname{sgn}(y)}{2}, \operatorname{sgn}(x)=\left\{\begin{array}{lll}
1 & \text { dla } & x>0 \\
0 & x=0 \\
-1 & x<0
\end{array} .\right.
$$

W pracy [12] zaproponowano następujące przekształcenie (Załącznik $A$ ) oparte na prawie Hooke'a:

$$
W_{\eta}(t)=\left[\frac{1+v}{2 E}\left(\sigma_{\eta}(t)\right)^{\prime}-\frac{v}{2 E} \cdot \sigma_{\eta}(t) \cdot \sigma_{\mathrm{kk}}(t)\right] \operatorname{sgn}\left(\sigma_{\eta}\right)
$$

gdzie: $v$ - liczba Poissona, $E$ - moduł Young'a, $\sigma_{\eta}$ - naprężenie normalne w płaszczyźnie krytycznej o normalnej $\eta$,

$$
\sigma_{\mathrm{kk}}=\sigma_{\mathrm{x}}+\sigma_{\mathrm{y}}+\sigma_{\mathrm{z}}
$$

Orientacja płaszczyzny krytycznej wyznaczona została przez wektor normalny zgodny $z$ kierunkiem maksymalnego w dziedzinie czasu i orientacji naprężenia

Wyznaczenie położenia płaszczyzny krytycznej

\section{$\downarrow$}

Wyznaczenie przebiegu parametru energetycznego

Wyznaczenie trwałości zmęczeniowej

Rys. 3. Algorytm wyznaczania trwałości zmęczeniowej w warunkach obciążeń stałoamplitudowych

Fig. 3. Abridged algorithm for fatigue life evaluation under constant amplitude loading conditions 
normalnego. Takie założenie pozwoliło na uproszczenie zapisu proponowanej postaci parametru gęstości

Liczbę cykli do zniszczenia według modelu (5) wyznaczyć można na podstawie następującej zależności (Załącznik B):

$$
N_{f}=\left(\frac{F A T}{2 \sqrt{2 E W_{\eta \mathrm{a}}}}\right)^{m} \cdot 2 \cdot 10^{6}
$$

\section{Badania eksperymentalne}

Wyniki badań wykorzystane w tej pracy zostały opublikowane w [2]. Przedmiotem badań jest próbka ze stali S355N (materiał rodzimy) (rys. 1). Próbki wykonano u jednego dostawcy, przez spawanie dużych płyt stalowych, które następnie wycięto plazmowo do odpowiednich wymiarów. Spoiny wykonano techniką GMAW, przez nałożenie kilku warstw spoiny na wstępnie podgrzaną powierzchnię. Naprężenia własne w próbce zmierzono metodą nawiercania ślepego otworu. Przedstawione wyniki pomiarów naprężeń własnych osiowych oraz prostopadłych do osi wynoszą 103 i 96 MPa. Powierzchnie boczne próbek poddane zostały szlifowaniu w celu usunięcia niejednorodności będących skutkiem technologicznego procesu spawania. Nie zastosowano ujednoradniającej obróbki cieplnej ani dalszej obróbki spoiny. Kryterium zniszczenia to całkowite pęknięcie złącza.

Badania przeprowadzono na jednej próbce dla naprężeń nominalnych 150 i $200 \mathrm{MPa}$ oraz na dwóch próbkach dla naprężeń nominalnych równych $100 \mathrm{MPa}$. Trwałość eksperymentalna dla poziomu obciążenia odpowiadającego naprężeniu nominalnemu $100 \mathrm{MPa}$ jest wartością średnią geometryczną.

\section{Ocena trwałości zmęczeniowej}

Do wyznaczenia naprężeń wykorzystano metodę elementów skończonych z zastosowaniem analizy liniowej (model ciała liniowo-sprężystego) [13]. Model dyskretny wykorzystany do obliczeń metoda promienia fikcyjnego oraz do obliczeń według modelu energetycznego przedstawiono na rysunku 4 . Kąt nachylenia lica spoiny $\theta$ wynosi $45^{\circ}$, co jest zgodne z zaleceniami dotyczącymi generowania modelu dyskretnego złącza ze spoiną pachwinową [3]. Fikcyjny promień zaokrąglenia $\rho_{f}$ został zamodelowany zgodnie $z$ rysunkiem 2 .

W celu wyznaczenia trwałości zmęczeniowej metodą naprężeń nominalnych rozważany element spawany (rys. 1) został przypisany do przypadku 511 wg rozdziału 3.2 zaleceń IIW [3]. Trwałość zmęczeniowa została wyznaczona zgodnie z zależnością (1) i z wykorzystaniem charakterystyki zmęczeniowej FAT 80.

W metodzie promienia fikcyjnego jako naprężeniowy parametr uszkodzenia dla charakterystyki zmęczeniowej przyjęto maksymalną wartość zakresu naprężenia zredukowanego $\sigma_{\text {eq }}$ (hipoteza Hubera-Misesa-Hencky'ego) w elemencie skończonym znajdującym się w linii wtopienia. Schematyczny rozkład naprężeń w otoczeniu linii wtopienia oraz lokalizację elementu skończonego wykorzystanego do obliczeń przedstawiono na rysunku 5.

Nowością przedstawioną $w$ tej pracy jest opisany model energetyczny wyznaczania trwałości zmęczeniowej, opisany przez zależność (5). W celu wykorzystania tego modelu do zagadnienia szacowania trwałości zmęczeniowej złączy spawanych zaproponowano: zastosowanie energetycznego kryterium parametru gęstości energii odkształcenia normalnego $W_{\eta}$ w płaszczyźnie krytycznej w połączeniu z ideą metody promienia fikcyjnego wykorzystaną jako efektywne podejście do problemu wyznaczania rozkładu naprężeń w złączu spawanym.

Aby wyznaczyć trwałość zmęczeniową według takiego podejścia, należy znać orientację płaszczyzny krytycznej. W tej pracy orientacja płaszczyzny



Rys. 4. Model dyskretny z zadanym obciążeniem i warunkami brzegowymi

Fig. 4. Discrete model together with the loading and boundary conditions

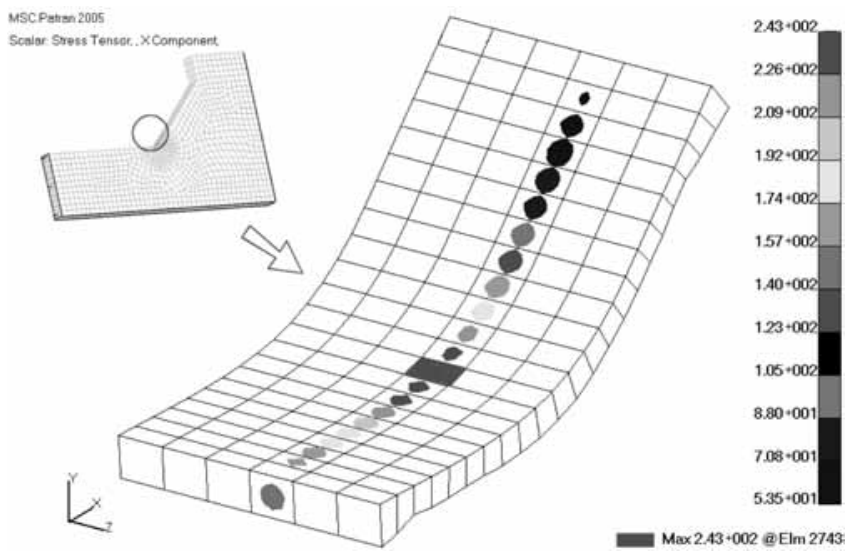

Rys. 5. Schematyczny rozkład naprężeń normalnych $\sigma_{x}$ w otoczeniu linii wtopienia (wartość nominalna $\sigma_{x}=100 \mathrm{MPa}$ )

Fig. 5. Schematic $\sigma_{x}$ stress distribution across the fusion line (nominal stress $\sigma_{x}$ stated at a level of $100 \mathrm{MPa}$ ) 


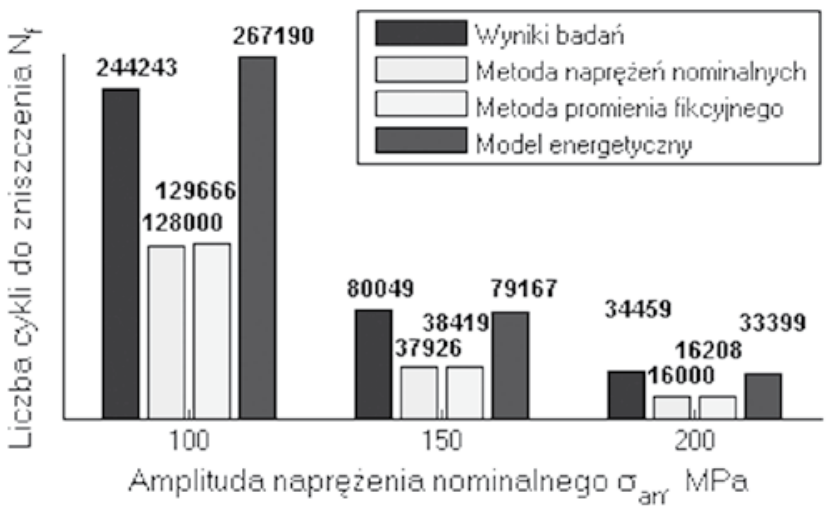

Rys. 6. Porównanie wyników badań i wyników obliczeń

Fig 6. Comparative graph for fatigue lives derived from tests and predicted with different approaches

\section{Załącznik A}

Parametr gęstości energii odkształcenia normalnego dla modelu ciała liniowo - sprężystego

Parametr $W_{\eta}$ gęstości energii odkształcenia normalnego w płaszczyźnie krytycznej, zaproponowany przez Łagodę [12], ma następującą postać:

$$
W_{\eta}(t)=\frac{1}{2} \cdot \sigma_{\eta}(t) \cdot \varepsilon_{\eta}(t) \cdot \operatorname{sgn}\left(\sigma_{\eta}, \varepsilon_{\eta}\right)
$$

gdzie naprężenia $\sigma_{\eta}$ i odkształcenia $\varepsilon_{\eta}$ normalne w kierunku wektora $\eta$ można wyrazić za pomocą notacji tensorowej:

$$
\begin{aligned}
& \sigma_{\eta}=\sigma_{\mathrm{ij}} n_{\mathrm{i}} n_{\mathrm{j}} \\
& \varepsilon_{\eta}=\varepsilon_{\mathrm{ij}} n_{\mathrm{i}} n_{\mathrm{j}}
\end{aligned}
$$

Wielkości z indeksami o czcionce prostej oznaczają obiekty tensorowe, a wielkości z indeksami pochylonymi to wielkości skalarne.

Wektor $n$ określający orientację płaszczyzny ma następujące składowe: $n_{\mathrm{i}}=\left[n_{\mathrm{x}} n_{\mathrm{y}} n_{\mathrm{z}}\right],(i=x, y, z)$, a $\sigma_{i j}$ to składowe tensora naprężenia, zaś $\varepsilon_{\mathrm{ij}}$ to składowe tensora odkształcenia.

Wykorzystując model ciała liniowo-sprężystego, składowe tensora odkształcenia $\varepsilon_{\mathrm{ij}}$ wyrażają się poprzez składowe tensora naprężenia:

$$
\varepsilon_{\mathrm{ij}}=\frac{1+v}{E} \sigma_{\mathrm{ij}}-\frac{v}{E} \sigma_{\mathrm{kk}} \delta_{\mathrm{ij}}
$$

gdzie: $E$ - moduł sprężystości wzdłużnej, $v$ - liczba Poissona, $\sigma_{k k}=\sigma_{x}+\sigma_{y}+\sigma_{z}, \delta_{i j}-$ delta Kroneckera, $\sigma_{k k}=\sigma_{x}+\sigma_{y}+\sigma_{z}$.

Zastosowanie zależności (A4) do (A3) prowadzi do następującego wzoru

$$
\varepsilon_{\eta}=\left(\frac{1+v}{E} \sigma_{i j}-\frac{v}{E} \cdot \sigma_{k k} \cdot \delta_{i j}\right) n_{\mathrm{i}} \cdot n_{\mathrm{j}}=\frac{1+v}{E} \sigma_{\mathrm{ij}} \cdot n_{\mathrm{i}} \cdot n_{\mathrm{j}}-\frac{v}{E} \cdot \sigma_{\mathrm{kk}} \cdot \delta_{\mathrm{ij}} \cdot n_{\mathrm{i}} \cdot n_{\mathrm{j}}
$$

przy czym należy pamiętać, że $\sigma_{i j} \cdot n_{i} \cdot n_{j}=\sigma_{n}$ (A2) oraz $\delta_{\mathrm{ij} x} \cdot n_{\mathrm{i}} \cdot n_{\mathrm{j}}=n_{\mathrm{x}}{ }^{2} \cdot n_{\mathrm{y}}{ }^{2} \cdot n_{\mathrm{z}}{ }^{2}=1$. Ostatecznie otrzymuje się:

$$
\varepsilon_{\eta}=\frac{1+v}{E} \sigma_{\eta}-\frac{v}{E} \cdot \sigma_{\mathrm{kk}}
$$

krytycznej zdefiniowana została przez wektor normalny zgodny z kierunkiem maksymalnego naprężenia normalnego. Wartość parametru gęstości energii odkształceń normalnych $W_{n}$ w płaszczyźnie krytycznej obliczono za pomocą zależności (5) przy podstawieniu wartości maksymalnego naprężenia głównego w miejsce naprężenia $\sigma_{\eta}$ (Załącznik A). W tym przypadku (wytężeniowe kryterium maksymalnych naprężeń normalnych) model dyskretny powinien zawierać fikcyjny promień zaokrąglenia $\rho_{f}$ równy $0,8 \mathrm{~mm}$ $\left(\rho_{f}=\rho+s \cdot \rho^{*}=0+2 \cdot 0,4=0,8\right.$, zgodnie z $\left.(2)\right)[2,10]$. Do wyznaczenia trwałości zmęczeniowej wykorzystano, tak jak dla metody promienia fikcyjnego, charakterystykę zmęczeniową FAT 225.

Porównanie trwałości obliczeniowej z eksperymentalną przedstawiono na rysunku 6.

Zastosowanie zależności (A6) do wyrażenia (A1) na parametr energetyczny $W_{\eta}$ prowadzi do następującej postaci:

$$
W_{\eta}(t)=\frac{1}{2} \sigma_{\eta}(t)\left(\frac{1+v}{E} \sigma_{\eta}(t)-\frac{v}{E} \cdot \sigma_{k k}(t)\right) \operatorname{sgn}\left(\sigma_{\eta}, \varepsilon_{\eta}\right)
$$

przy czym dla liniowo - sprężystego modelu ciała prawdziwe jest

$$
\operatorname{sgn}\left(\sigma_{\eta}, \varepsilon_{\eta}\right)=\operatorname{sgn}\left(\sigma_{\eta}\right)=\operatorname{sgn}\left(\varepsilon_{\eta}\right)
$$

Końcowa postać wyrażenia na parametr $W_{\eta}$ gęstości energii odkształcenia normalnego w płaszczyźnie krytycznej jest następująca

$$
W_{\eta}(t)=\left[\frac{1+v}{2 E}\left(\sigma_{\eta}(t)\right)^{\prime}-\frac{v}{2 E} \cdot \sigma_{\eta}(t) \cdot \sigma_{\mathrm{kk}}(t)\right] \operatorname{sgn}\left(\sigma_{\eta}\right)
$$

Rozpatrując w uproszczeniu tylko amplitudy naprężeń, otrzymuje się

$$
W_{\eta \mathrm{a}}=\frac{1+v}{2 E} \sigma_{\eta \mathrm{a}}^{2}-\frac{v}{2 E} \cdot \sigma_{\eta \mathrm{a}} \sigma_{\mathrm{kk}}
$$

Zakładając dodatkowo, że mamy do czynienia z obciążeniem cyklicznym, a składowe obciążenia zmieniają się proporcjonalnie, to kierunek i wartość maksymalnego naprężenia normalnego pokrywa się z kierunkiem i wartością maksymalnego naprężenia głównego $\sigma_{1}$. W związku z tym obliczenia numeryczne znacznie się upraszczają, a wyrażenie (A10) przyjmuje postać:

$$
W_{\eta 1}=\frac{1+v}{2 E} \sigma_{1}^{2}-\frac{v}{2 E} \cdot \sigma_{1} \sigma_{\mathrm{kk}}
$$




\section{Załącznik B}

Trwałość zmęczeniowa według parametru gęstości energii odkształcenia normalnego (A1)

Parametr ten wyraża się za pomocą parametru naprężeniowego stosowanego w charakterystykach FAT. Przyjmując kryterium uszkodzenia według parametru gęstości energii odkształcenia normalnego (A1) oraz jednoosiowy stan naprężenia, w którym tylko składowa $\delta_{\text {xa }}=\delta_{a}$ jest różna od zera, otrzymujemy

$$
W_{\mathrm{a}}=\frac{1+\mathrm{v}}{2 E} \sigma_{\mathrm{a}}^{2}-\frac{v}{2 E} \cdot \sigma_{\mathrm{a}} \sigma_{a}=\frac{\sigma_{\mathrm{a}}^{2}}{2 E}
$$

\section{Z zależności (B1) otrzymujemy}

$$
\sigma_{a}=\sqrt{2 E W_{\mathrm{a}}}
$$

W związku z tym amplituda parametru energetycznego $W_{\eta a}$ wyliczona przy wieloosiowym stanie naprężenia ulega przekształceniu według zależności (B2) w celu przystosowania jej do charakterystyk zmęczeniowych FAT. Ostatecznie otrzymywana jest zależność

$$
N_{f}=\left(\frac{F A T}{2 \sqrt{2 E W_{\eta \mathrm{a}}}}\right)^{m} \cdot 2 \cdot 10^{6}
$$

\section{Wnioski}

Na podstawie uzyskanych wyników obliczeń sformułowano następujące wnioski:

- metoda naprężeń nominalnych pozwala na szybką i dokładną ocenę trwałości zmęczeniowej, jednak jej zastosowanie ograniczone jest do złączy spawanych występujących w sklasyfikowanych elementach spawanych,

- zastosowanie metody promienia fikcyjnego pozwoliło na uzyskanie wyników trwałości zmęczeniowej porównywalnych do wyników otrzymanych po zastosowaniu metody naprężeń nominalnych,
- porównanie trwałości eksperymentalnej z trwałością obliczeniową wyznaczoną wg modelu energetycznego połączonego $\mathrm{z}$ metodą promienia fikcyjnego wykazało bardzo wysoką zgodność trwałości obliczeniowej z eksperymentalną, przy podwyższonym prawdopodobieństwie zniszczenia (powyżej 5\%),

- obliczenia trwałości zmęczeniowej według opisanego schematu dla przedstawionego modelu energetycznego wskazują na celowość zastosowania ww. metody do obliczeń skomplikowanych geometrycznie, niesklasyfikowanych elementów spawanych.

\section{Literatura}

[1] Sonsino C. M., Kaufmann H., Demofonti G., Rifisculi S., Sedlacek G., Müller C., Hanus F., Wegmann H. G.: HighStrength steels in welded state for light-weight constructions under high and variable stress peaks, ESCC Steel Research Programme, CSM - Roma, LBF - Darmstadt, Published by the European Commission, Brussels, 1999

[2] Łagoda T.: Trwałość zmęczeniowa wybranych złączy spawanych, Studia i monografie Politechniki Opolskiej, z.173, OW Politechniki Opolskiej, Opole, 2005.

[3] Hobbacher A.: Recomendations for fatigue design of welded joint and components, IIW document XIII-2151-07/XV-125407, Paris, May 2007.

[4] Eurocode 3: Design of Steel Structures - Part 1-1: General Rules for Buildings, ENV 1993-1-1, European Committee for Standardisation, Brussels 1992.

[5] Japanese Society of Steel Construction (JSSC): Fatigue design recommendations for steel structures [English Version], JSSC Technical Report No. 32. Tokyo: JSSC; 1995.

[6] Łagoda T.: Wyznaczanie trwałości zmęczeniowej złączy spawanych według naprężeń nominalnych, Spajanie materiałów konstrukcyjnych, $\mathrm{nr} 2$ (4)/2009, s. 10-14.

[7] Łukasik T.: Wyznaczanie trwałości zmęczeniowej konstrukcji spawanej metodą linearyzacji naprężeń w punkcie krytycznym, Przegląd Spawalnictwa, nr 4/2010, s. 19-25.

[8] Morgenstern C., Sonsino C.M, Hobbacher A., Sorbo F.: Fatigue design of aluminium welded joints by the local stress concept with the fictitious notch radius of $r_{f}=1 \mathrm{~mm}$, International Journal of Fatigue 28, 2006, s. 881-990.

[9] Radaj D., Sonsino C.M., Fricke W.: Fatigue assessment of welded joints by local approaches, second edition, Woodhead Publishing and CRC Press, Cambridge and Roca Baton, 2006.

[10] Neuber H.: Über die Berücksichtigung der Spannungskonzentration bei Festigkeitsberechnungen, Konstruktion 20 (7), 1968, s. 245-251.

[11] Berto F., Lazzarin P., Radaj D.: Fictitious notch rounding concept applied to sharp V-notches: Evaluation of the microstructural support factor for different failure hypotheses. Part I: Basic stress equations, Engineering Fracture Mechanics 75,2008 , s. 3060-3072.

[12] Łagoda T.: Energetyczne modele oceny trwałości zmęczeniowej materiałów konstrukcyjnych w warunkach jednoosiowych i wieloosiowych obciążeń losowych, Studia i monografie Politechniki Opolskiej, z.121, OW Politechniki Opolskiej, Opole, 2001.

[13] MSC/PATRAN, MSC. The MacNeal-Schwendler Corporation, ver. 2005

Praca współfinansowana ze środków Europejskiego Funduszu Społecznego (Work co-financed by European Social Fund) 